\title{
Tipificación de Arnica montana L. (Asteraceae)
}

\section{Pedro Pablo Ferrer-Gallego \\ Emilio Laguna}

Centro para la Investigación y Experimentación Forestal (CIEF). Servicio de Vida Silvestre. Generalitat Valenciana.

Avda. Comarques del País Valencià, 114. 46930 Quart de Poblet (València)

flora.cief@gva.es

\section{Roberto Roselló Gimeno}

IES Jaume I

Plaça Sanchis Guarner, s/n. 12530 Borriana (Castelló)

rrosello514@cv.gva.es

\section{Juan B. Peris Gisbert}

Gerardo Stübing

Universitat de València. Departament de Botànica

Avda. Dr. Moliner, 50. 46100 Burjassot (València)

jbperis@uv.es

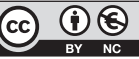

Manuscrito recibido en agosto de 2013

\section{Resumen}

Se designa un lectótipo para Arnica montana L. (Asteraceae) a partir del material original de Linneo conservado en el herbario UPS-BURSER.

Palabras clave: Arnica; Asteraceae; Linneo; nomenclatura; tipificación.

Abstract. Lectotypification of Arnica montana L. (Asteraceae)

A lectotype for Arnica montana L. (Asteraceae) is designated from Linnaeus' original material preserved in the UPS-BURSER herbarium.

Keywords: Arnica; Asteraceae; Linnaeus; nomenclature; typification.

\section{Introducción}

Arnica montana L. (Asteraceae) es una especie herbácea, perenne y rizomatosa, distribuida por Europa (Ferguson, 1976); desde el sureste de Escandinavia al noreste de Italia y entre los Cárpatos y norte de la península Ibérica (Maguire, 1943; Wagner, 1982). Habita en prados y claros de bosque, en zonas húmedas o secas y en suelos silíceos. Es una planta utilizada desde muy antiguo por sus propiedades 
medicinales (Mattioli, 1565; Sala, 1786) relacionadas con sus efectos bacteriostáticos, antihiperlipidémicos, antiinflamatorios, antirreumáticos, cardiotónicos y fungistáticos (Willuhn, 1991).

En la actualidad este nombre no cuenta con la designación de su correspondiente tipo nomenclatural, por lo que en el presente trabajo se aborda su lectotipificación a partir de la consulta de las diferentes obras bibliográficas citadas en el protólogo y del estudio de los materiales originales de Linneo previamente identificados por Jarvis (2007: 316).

Entre los sinónimos citados por Linneo (1753: 884) en el protólogo de la especie, aparece el nombre de Caspar Bauhin «Doronicum, plantaginis folio, alterum» publicado en su obra Pinax theatri botanici... (Bauhin, 1623). Tras la consulta del herbario UPS-BURSER, hemos localizado un pliego con material perteneciente a esta especie [Herb. Burser X: 20], en cuya etiqueta aparece escrito: Doronicum plantaginis folio al. / terum Bauh. / Alisma Matth. [...]. Este pliego contiene una roseta de hojas y un ejemplar completo en flor en buen estado de conservación, que se ajusta al protólogo linneano y permite conservar el uso tradicional y actual de este nombre. Como el herbario de Joachin Burser, está organizado de acuerdo con la obra de su maestro Caspar Bauhin arriba citada. Esta obra y el mencionado herbario están por consiguiente vinculados. Este herbario estaba depositado en Uppsala cuando fue utilizado por Linneo para la interpretación de los nombres que aparecen en la obra de Bauhin, por lo que el pliego de Burser X: 20 (UPS-BURSER) se trata de un material original sobre el que poder tipificar el nombre de Linneo.

Asimismo, Linneo incluye también dentro del protólogo dos sinónimos que están ilustrados por sendos iconos; el publicado por Reneaulme (1611: 119) con el nombre de «Diuretica», y el de Mattioli (1565: 934), con el desacertado nombre de «Alisma», pues según indica Sala (1786: 11-12), Mattioli no reconoció en un primer momento en el llantén acuático, actual Alisma plantago-aquatica L., la Alisma de Dioscórides, y se refirió con este nombre a la árnica (Fig. 1). Estos dos excelentes grabados muestran con gran detalle importantes caracteres diagnósticos de la especie. No obstante, como existe un pliego en la colección de Burser y éste muestra un buen estado de conservación, consideramos más adecuado designar este material como el tipo del nombre linneano.

Por otra parte, existe un pliego en el herbario de Linneo [Herb. Linn. No. 1001.1 (LINN)] que contiene tres fragmentos en buen estado de conservación, dos de ellos con hojas y flores (http://www.linnean-online.org/10382/); sin embargo, consideramos que este material no es original de Linneo ya que no lleva anotado en la base del pliego, con letra del propio Linneo, el doble código con el que este autor reconocía sus especies descritas en la primera edición de Species Plantarum de 1753, código compuesto por el número con el que figura la especie en la obra más el epíteto que Linneo indicaba en el margen para cada especie (Turland \& Jarvis, 1997; Turland, 2006; Jarvis, 2007; López González \& Morales, 2011), para este caso «1 Montana». Por lo tanto, la consideración de este material para ser designado como lectótipo de Arnica montana queda desestimada. 

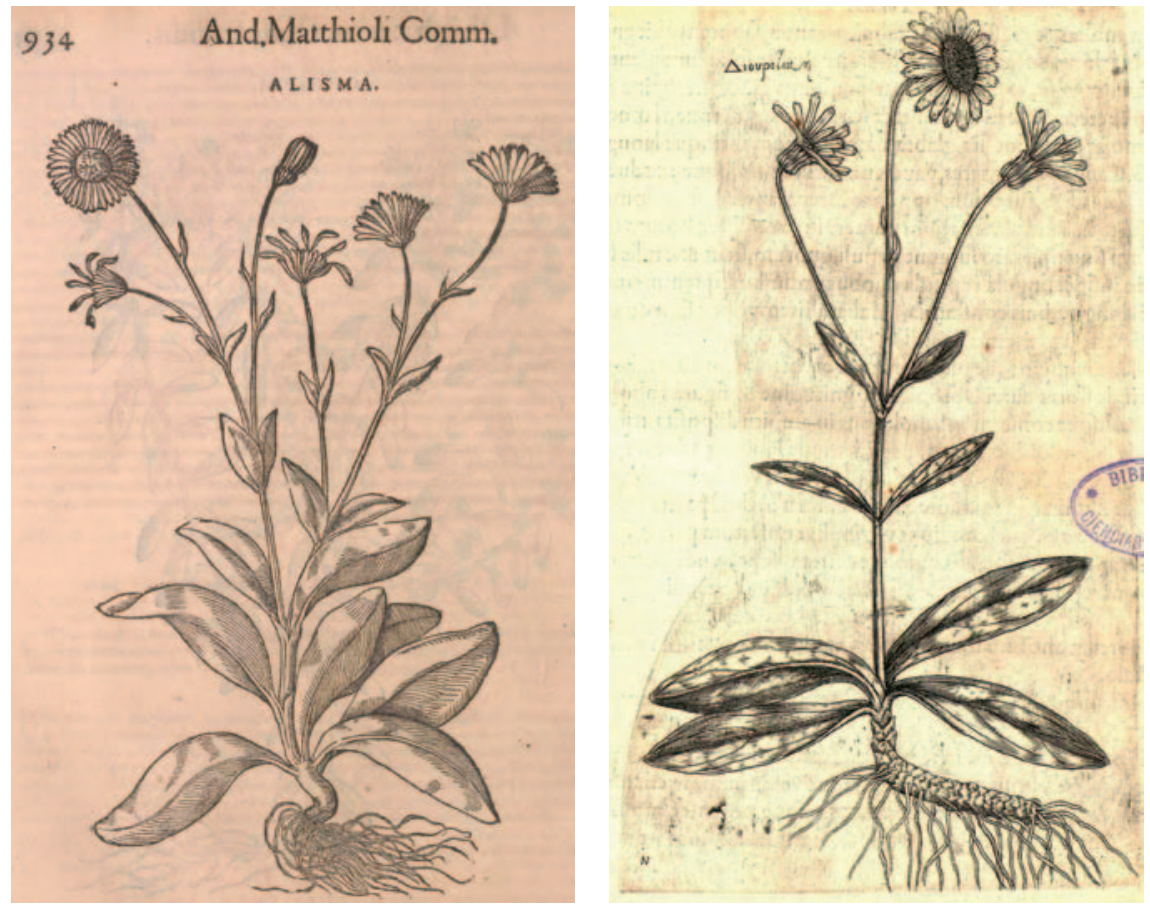

Figura 1. Icono de Mattioli (1565: 934) «Alisma» (izquierda) e icono de Reneaulme (1611: 119) «Diuretica» (derecha).

\section{Tipificación}

Arnica montana L., Sp. Pl.: 884 (1753)

Ind. loc.: «Habitat in Alpibus \& pratis Europae frigidioris» Lectotypus (hic designatus): Herb. Burser X: 20 (UPS-BURSER) (el lectótipo es el ejemplar completo en flor que contiene el pliego) (Fig. 2)

Dentro de Arnica montana, Linneo incluyó una variedad denominada con el epíteto alpina, caracterizada por presentar hojas lanceoladas en vez de ovadas, como en la forma tipo. Esta variedad fue posteriormente recombinada con estatus subespecífico como Arnica angustifolia subsp. alpina (L.) I.K. Ferguson (Ferguson, 1973: 282). El único material original disponible que hemos localizado sobre el que poder lectotipificar este nombre es el icono de Tabernaemontanus (1590: 336). Se propone, por tanto, lo siguiente:

Arnica montana var. alpina L., Sp. Pl.: 884 (1753)

Lectotypus (hic designatus): [icono] in Tabernaemontanus, Eicones Pl.: 336 (1590) (Fig. 3). 


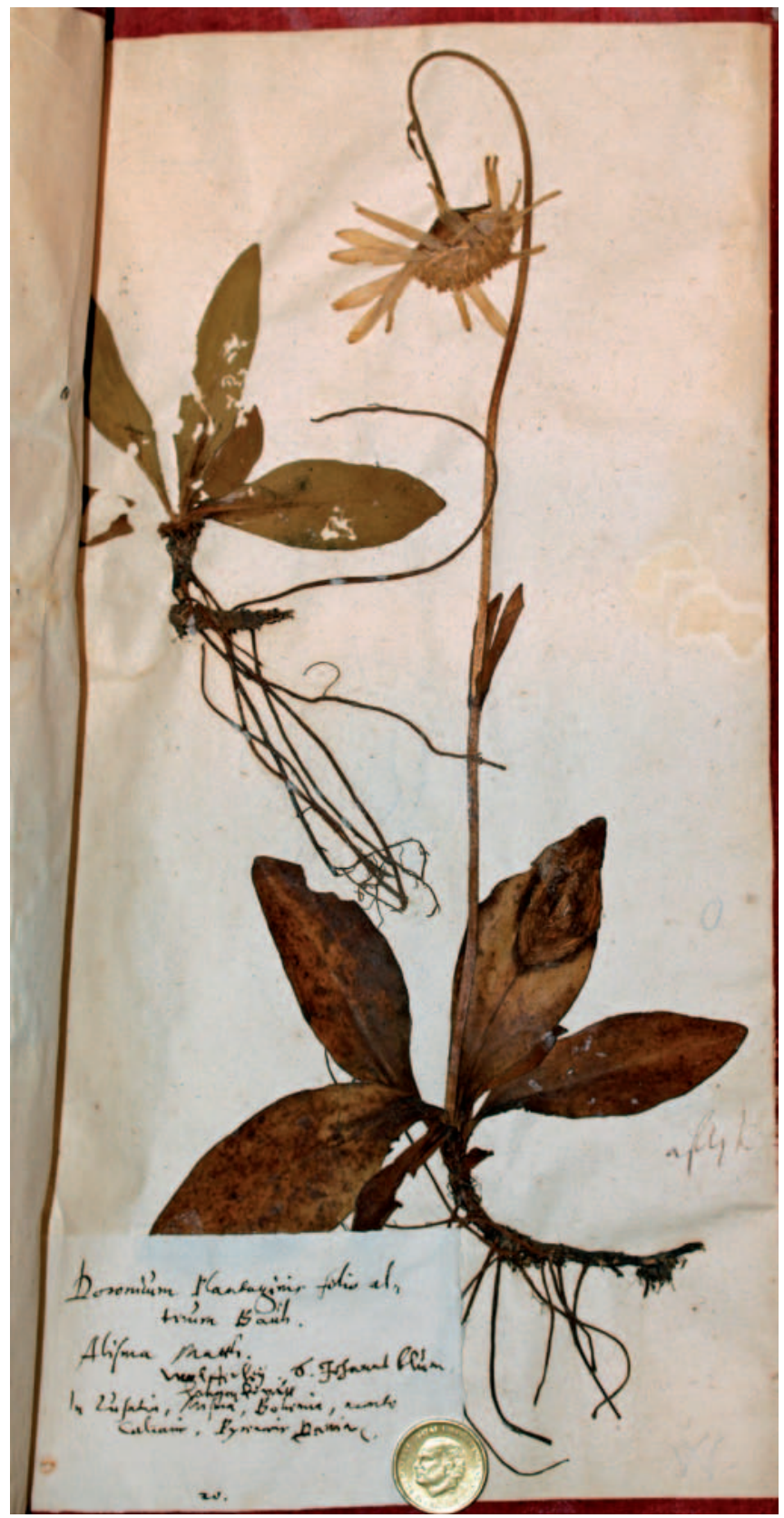

Figura 2. Lectótipo de Arnica montana L., Herb. Burser X: 20 (UPS-BURSER) (el lectótipo es el ejemplar completo en flor que contiene el pliego). Herbario UPS, reproducido con permiso. 


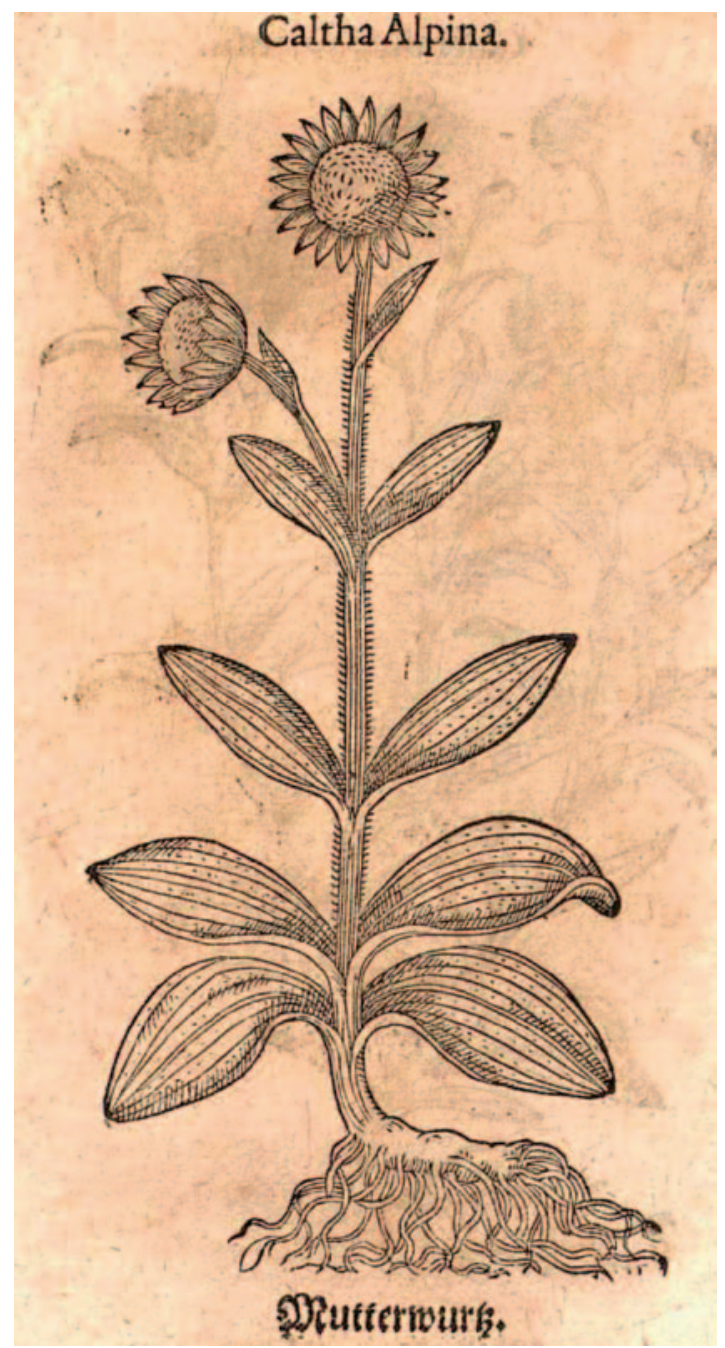

Figura 3. Lectótipo (iconolectótipo) de Arnica montana var. alpina L., [icono] in Tabernaemontanus, Eicones Pl.: 336 (1590).

\section{Agradecimientos}

Al Dr. Mats Hjertson (Museum of Evolution, Botany Section Uppsala University) y las Dras. Elaine Charwat y Lynda Brooks (The Linnean Society of London) por su ayuda en el estudio de los herbarios UPS-BURSER y LINN respectivamente. Agradecemos asimismo al Dr. Llorenç Sáez (Facultat de Biociències, Universitat Autònoma de Barcelona) y al Dr. Carles Benedí (Facultat de Farmàcia, Universitat de Barcelona) la revisión crítica del manuscrito. 


\section{Referencias bibliográficas}

Bauhin, C. 1623. Pinax theatri botanici. Basileae Helvet.: Sumptibus \& typis Ludovici Regis, Switzerland.

Ferguson, I.K. 1973. Compositae. (229) Arnica L. In: Heywood, V.H. (Ed.). Flora Europaea: Notulae Systematicae ad Floram Europaeam spectantes. No. 14. Bot. J. Linn. Soc. 67(3): 282.

Ferguson, I.K. 1976. Arnica L. In: Tutin, T.G.; Heywood, V.H.; Burges, N.A.; Moore, D.M.; Valentine, D.H.; Walters S.M.; Webb, D.A. (Eds.): Flora Europaea 4: 189-190. Cambridge University Press. Cambridge.

Jarvis, C.E. 2007. Order out the Chaos. Linnean plant names and their types. The Linnean Society of London in association with the Natural History Museum, London. London.

Linneo, C. 1753. Species Plantarum. Stockholm.

López González, G.; Morales, R. 2011. Sobre los tipos nomenclaturales de algunas especies linneanas de Teucrium, Phlomis y Thymus (Labiatae). Acta. Bot. Malacitana 36: 107-112.

Maguire, B. 1943. A monograph of the genus Arnica (Senecioneae, Compositae). Brittonia 4(3): 386-510.

Mattioli, P.A. 1565. Commentarii in sex libros Pedacii Dioscoridis Anazarbei de medica materia. Venice: oficina valgresiana.

Reneaulme, P. 1611. Specimen historiae plantarum. Paris.

Sala, A. 1786. Memoria sobre el árnica de los montes. Leída a la Real Academia de Ciencias Naturales y Artes de Barcelona. Barcelona.

Tabernaemontanus, J.T. 1590. Eicones plantarum. Frankfurt am Main.

Turland, N.J. 2006. Lectotypification of Campanula saxatilis, Phyteuma pinnatum and Verbascum arcturus, Linnaean names of three taxa endemic to Crete. Willdenowia 36 (Special Issue): 303-309.

Turland, N.J.; Jarvis, C.E. 1997. Typification of Linnaean specific and varietal names in the Leguminosae (Fabaceae). Taxon 46: 457-485.

Wagner, H. 1982. Pharmazeutische Biologie. Drogen und ihre Inhalstsstoffe. Fischer, Sttugart.

Willuhn, G. 1991. Arnica montana L. Porträt einer Arzneipflanze. Pharm. Zgt. 136: 24532478. 